\title{
EFEKTIVITAS LAYANAN INFORMASI KARIER DENGAN MENGGUNAKAN TEKNIK LIVE MODELING DAN SYMBOLIC MODELING UNTUK MENINGKATKAN PEMAHAMAN KARIER SISWA
}

\author{
Teuku Fadhli \\ Universitas Jabal Ghafur Sigli \\ teukufadhligp@gmail.com / 0852-6020-0442
}

\begin{abstract}
ABSTRAK
Rendahnya tingkat pemahaman karier siswa dipengaruhi oleh minimnya informasi karier mengenai pekerjaan dan pendidikan untuk mendukung sebuah pekerjaan dimasa akan datang. Tujuan dari penelitian ini adalah untuk menguji keefektifan layanan informasi karier dengan teknik live modeling dan symbolic modeling untuk meningkatkan pemahaman karier siwa. Metode penelitian yang digunakan adalah eksperimen, dengan desain Non Equivalent Group Pretest-Postest Control Group, subyek penelitian sebanyak 96 orang siswa kelas IX SMP Teuku Umar yang dibagi menjadi tiga kelompok, yakni kelompok A, B dan Kontrol. Hasil analisis data One way ANOVA menunjukkan bahwa teknik live modeling dan symbolic modeling $(\mathrm{p}<0.01 ; \mathrm{F}=108.015)$. Sedangkan pengujian post hoc test menunjukkan ( $\mathrm{MD}=-1.81 ; \mathrm{p}=0.97>0.05)$ yang berarti teknik live modeling dan symbolic modeling tidak terdapat perbedaan rata-rata signifikan, untuk teknik live modeling dan kelompok kontrol dengan( $\mathrm{MD}=-59.28 ; \mathrm{p}<0.01)$, dan untuk teknik symbolic modeling dan kelompok kontrol dengan $(\mathrm{MD}=-6109$; $\mathrm{p}<0.01$ ), yang berarti teknik live modeling dan symbolic modeling rata-rata efektif untuk meningkatkan pemahaman karier siswa siswa SMP Teuku Umar Semarang.
\end{abstract}

Kata Kunci : Layanan Informasi, Live Modeling, Symbolic Modeling, Pemahaman Karier

\section{ABSTRACT}

The students' low understanding in career is influenced by alack of information about career and education in which those aspects are needed to realize a certain job in the future. This study aims to examine the effectiveness of career information services with live and symbolic modeling techniques to improve students' career understanding. The research method used is experimental with operating Non Equivalent Group Pretest-Postest Control Group design, 96 students of $9^{\text {th }}$ grade of SMP Teuku Umar shared in 3 classes were employed as subject, namely is $A, B$ and Control group. The one-way data analysis shows the technique of live and symbolic modeling whereas $(p<0.01 ; \mathrm{F}=108.015)$. While the post hoc test shows $(M D=-1.81 ; p=0.97>0.05)$, it means there is no significant difference both live and symbolic modeling techniques. In addition, it is also known that live modeling and control group whereas $(M D=-59.28 ; p<0.01)$, symbolic modeling and control group whereas $(M D=-6109 ; p<0.01)$. Therefore, it could be concluded that live and symbolic modeling technique is effective to improve students' career understanding at SMP Teuku Umar Semarang.

Keywords: Career Information, , Live Modeling, Symbolic Modeling, Understanding Career

Dipublikasikan Oleh :

UPT Publikasi dan Pengelolaan Jurnal

Universitas Islam Kalimantan Muhammad Arsyad Al-Banjari Banjarmasin 


\section{PENDAHULUAN}

Siswa-siswa ditingkat Sekolah Menegah Pertama, tentu sudah seharusnya dibekali dengan berbagai informasi terkait karier sebagai upaya mengarahkan dan memotivasikan diri dalam mencapai tugas-tugas perkembangan karier (Hirschi, Lee, Porfeli, \& Vondracek, 2013). Sebagaimana (Feldman, Olds, \& Papalia 2009:17) masa remaja merupakan periode transisi antara masa anak- anak dan masa dewasa.

Jasmi, A. et al., (2015) dalam penelitiannya memberi dua implikasi teoritis. Pertama diasumsikan individu yang berada pada tahap transisi harus menjelajahi informasi yang berhubungan dengan karier. Kedua eksplorasi informasi diri invidu akan memicu minat, kepuasan dan membuat invidu lebih percaya diri dan mampu untuk membuat penilaian berdasarkan informasi karier. Meningkatnya kemampuan Individu dalam memahami karier mereka sangat dimungkinkan apabila ada lingkungan yang dapat merangsang mereka ke arah itu (Medina, 2010). Hal ini sesuai dengan penjelasan oleh Bandura (Brown, 2007: 126) dalam Teori Sosial Kognitif mengemukakan karier dapat ditingkatkan melalui pengalaman, belajar, motivasi dan dorongan serta interaksi individu dengan lingkungan.

Trusty, et al, (2012) yang menyatakan bahwa siswa-siswa SMP sangat membutuhkan pendidikan karier yang efektif. Jennifer, N. K. (2010) juga menyatakan bahwa siswa perlu menyusun rencana yang tepat dalam menentukan pilihan untuk kehidupannya, agar tidak menyimpang dalam menentukan pilihan hidup dimasa depan. Pendidikan karier yang efektif dimaksudkan adalah untuk membantu siswa dalam pendidikan supaya dapat mengembangkan pemahaman karier. Pemahaman karier siswa di sekolah merupakan aspek paling penting dalam pendidikan yang harus dimiliki oleh setiap siswa di sekolah.

Kantrov (2015) dalam penelitiannya yang di lakukannya pada Academy of Information Technology and Robotics (AITR) melaporkan bahwa meningkatnya kemampuan karier siswa di AITR salah satunya intervensi yang di terapkan adalah dengan menciptakan sistem belajar yang bermakna yang memungkinkan siswa untuk belajar dan menerapkan pengetahuan dan keterampilan akademik dan teknik untuk tantangan dunia kerja.

Rendahnya pemahaman karier siswa-siswa di SMP Teuku Umar Semarang tentu tidak terlepas dari berbagai permasalahan, sehingga menarik untuk di kaji berdasarkan rujukan-rujukan literatur pendukung, sebagaimana penelitian Budiman dalam (Atmaja, 2014) yang melaporkan bahwa $90 \%$ siswa SMA di Kabupaten Bandung menyatakan bimbang dalam memilih kariernya. Selain itu, Mustika (2014) dalam penelitiannya juga melaporkan bahwa siswa SMK
PGRI Wonoasri memiliki tingkat pemahaman karier yang rendah.

Pendidikan karier yang tepat harus di berikan secara intensif dan akan menghasilkan lebih banyak intrinsik termotivasi siswa karena akan membantu siswa mengembangkan identitas karier (Geurts \& Meijers, 2009). Schmidt (2008: 108) mengemukakan bahwa layanan informasi karier dapat membantu siswa untuk mempersiapkan diri dalam menentukan apa yang ingin di capai dan dipilih atas kesadaranya tanpa paksaan dan intevensi siapapun. Kevin B. Stoltz \& Tabitha L. Young, (2012) menggungkapkan bahwa invidu mesti didorong untuk mengeksplo-rasi dilema karier dan memungkinkan individu tersebut untuk memelihara dan meningkatkan potensi diri, secara terus-menerus dengan ber-adaptasi.

Seperti pengetahuan yang berhubungan dengan karier atau konsep diri yang terkait dengan pengembangan karier. Selain itu, Whiston, et al dalam (Meijers, F 2013) juga mengungkapkan bahwa intervensi karier yang mencoba untuk membantu siswa dalam merencanakan dan mempersiapkan diri untuk bekerja, memiliki dampak paling besar pada pengembangan karier terhadap keterampilan pengambilan keputusan, dibandingkan dengan keterampilan lain,

Teknik live modeling merupakan teknik yang dapat memberi efek intervensi secara langsung kepada siswa dengan cara mendatangkan narasumber dari luar sebagai pedoman hidup untuk dipahami bagi siswa, dengan kata lain siswa dapat mengamati lansung contoh yang nyata (contoh hidup) sebagai pedomannya (Eford, 2016: 340). Sebagaimana (Hirschi \& Lage, 2008) dalam penelitian yang lakukannya terhadap 330 siswa kelas VII di Swiss dengan menggunakan teknik CIP (Cognitive Information Proces) terdapat keter-batasan yang berdampak pada perkembangan kesiapan karier dikarenakan intervensi yang di berikan bukanlah contoh (model perilaku) yang di tunjukkan secara lansung. Dalam penelitian (Meijers, 2008) juga melaporkan bahwa intervensi yang terfokus untuk membantu siswa supaya berprestasi saja, tidak akan memberi efek positif terhadap pemahaman siswa dalam mempersiapkan diri untuk berkarier.

Sedangkan symbolic modeling merupakan cara/prosedur yang dilakukan dengan melibatkan dan mengilustrasikan perilaku (model) yang ingin dicapai melalui video atau audio (Erford, 2016: 340). Penelitian Sally E. Rooke, John M. Malouf (2006) memberikan bukti bahwa intervensi symbolic modeling memberi penguatan dan dapat mengurangi coping stress individu. Oleh karena itu, menarik bagi peneliti ingin melakukan penelitian dengan layanan informasi karier menggunakan teknik live modeling dan symbolic modeling terhadap siswa untuk meningkatkan pemahaman kariernya. 
Berdasarkan uraian dan kajian-kajian dari berbagai literasi diatas, maka tujuan dari penelitian ini adalah untuk mengetahui apakah layanan informasi karier dengan menggunakan teknik live modeling dan symbolic modeling efektif untuk meningkatkan pemahaman karier siswa SMP Teuku Umar Semarang.

Hasil penelitian ini diharapkan agar konselor sekolah diperlukan persiapan matang dengan bantuan yang tepat dan terencana untuk kebutuhan masa depan siswa, dengan cara memberikan pendidikan karier melalui layanan bimbingan dan konseling yaitu dengan layanan informasi secara intensif dan berkelanjutan kepada siswa.

\section{METODE}

Dalam penelitian ini, peneliti menggunakan metode penelitian eksperimen dalam bentuk rancangan penelitian Non Equivalent Group Pretest-
Postest Control Group. Sesuai dengan rancangan dalam penelitian ini, peneliti memberikan posttest dan pretest kepada kelompok eksperimen dan kontrol, dengan melakukan penetapan subjek yang menjadi anggota kelompok eksperimen dan anggota kelompok kontrol sebelum dilakukan pretest.

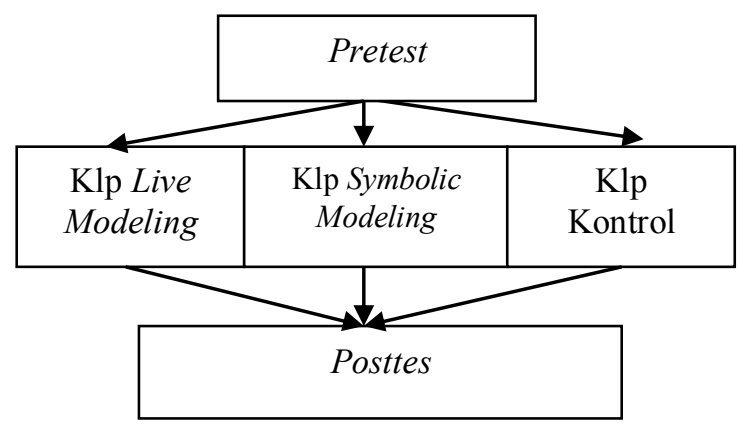

Gambar 1. Tahapan penelitian

Tabel 1. Perbandingan Kelompok Live Modeling, Symbolic Modeling dan Kontrol

\begin{tabular}{cccccccc}
\hline \multirow{2}{*}{ Parameter } & \multicolumn{2}{c}{ Pretest } & \multicolumn{2}{c}{ Posttest } & T & \multirow{2}{*}{ P } & \multirow{2}{*}{ F } \\
\cline { 2 - 5 } & Mean & SD & Mean & SD & (DF=31) & & \\
\hline LM & 117.75 & 13.088 & 178.94 & 95.270 & -19.68 & 0.01 & 108.105 \\
SM & 116.56 & 12.748 & 179.56 & 12.804 & -18.43 & 0.01 & \\
Kontrol & 116.63 & 11.126 & 118.53 & 14.582 & -0.545 & 0.58 & \\
\hline
\end{tabular}

Gain Skor: F (108.105; p < 0.01)

Subyek penelitian atau responden dalam penelitian ini adalah siswa SMP Teuku Umar Semarang yang memiliki tingkat pemahaman karier yang rendah. jumlah siswa atau sabyek penelitian yang di gunakan dalam penelitian ini 96 siswa yang dibagi dalam tiga kelompok, masing-masing dua kelompok eksperimen dan kelompok kontrol.

Teknik pengumpulan data yang digunakan untuk mengukur tingkat pemahaman karier siswa di SMP Teuku Umar adalah instrumen skla likert, disebut dengan skala pemahaman karier. Instrumen skala pemahaman karier (skla likert) akan dilakukan uji validasi ahli dan kemudian uji coba instrumen. Hasil uji validitas instrumen valid dengan tingkat signifikansinya $\mathrm{p}=0.01$ (validitas $\mathrm{r}_{\mathrm{xy}}=0.197-0.787$ ). Kemudian dilakukan uji normalitas dan homogenitas pretest dan posttest dengan uji Independent T-test. Data hasil penelitian yang didapatkan, akan di analisis menggunakan uji Paired sampel T-test dan One Way ANNOVA.

\section{HASIL DAN PEMBAHASAN}

Hasil penelitian ini akan dibahas dan diuraikan secara rinci berdasarkan dari analisis data hasil penelitian. Hasil uji Paired Samples T-test dalam penelitian ini menunjukkan bahwa nilai posttest dan pretest kelompok ekperimen A dan kelompok

Dipublikasikan Oleh :

UPT Publikasi dan Pengelolaan Jurnal

Universitas Islam Kalimantan Muhammad Arsyad Al-Banjari Banjarmasin ekperimen $\mathrm{B}$ dengan taraf signifikansi $\mathrm{p}<0.01$, maka Ha di terima dan Ho ditolak.

Hasil uji one way ANOVA post hoc test dalam penelitian ini menunjukkan nilai $\mathrm{F}=108.015$; dengan signifikansi $\mathrm{p}<0.01$, sehingga Ho ditolak atau terdapat perbedaan rata-rata antar setiap kelompok eksperimen.

Adapun hasil dari uji Post Hoc Test menjelaskan kelompok eksperimen live modeling, dan symbolic modeling tidak terdapat perbedaan rata-rata yang berarti dengan taraf signifikansi $0.972>0.050$, Kelompok eksperimen live modeling dengan kelompok kontrol terdapat perbedaan rata-rata yang berarti dengan taraf signifikansi $\mathrm{p}<0.01$, sedangkan kelompok eksperimen symbolic modeling dengan kelompok kontrol juga terdapat perbedaan rata-rata yang berarti dengan taraf signifikansi $\mathrm{p}<0.01$.

Tabel 2. Paired Samples T-test

\begin{tabular}{|c|c|c|c|c|}
\hline & & Mean & df & $\begin{array}{c}\text { Sig. (2- } \\
\text { tailed) }\end{array}$ \\
\hline Pair 1 & $\begin{array}{l}\text { PreA - } \\
\text { PosA }\end{array}$ & -61.188 & 31 & .001 \\
\hline Pair 2 & $\begin{array}{l}\text { PreB - } \\
\text { PosB }\end{array}$ & -63.000 & 31 & .001 \\
\hline Pair 3 & $\begin{array}{l}\text { PreKtrl- } \\
\text { PosKtrl }\end{array}$ & -1.906 & 31 & .589 \\
\hline
\end{tabular}


Dari hasil Uji T-test menunjukkan adanya peningkatan rat-rata yang signifikan terhadap kelompok eksperimen teknik live modeling dan kelompok teknik symbolic modeling. Sehingga dapat disimpulkan bahwa layanan informasi karier live modeling dan symbolic modeling efektif untuk meningkatkan pemahaman karier siswa. Efektifnya layanan informasi karier dengan menggunakan teknik live modeling dan teknik symbolic modeling ditinjau dari proses permulaannya yaitu pelaksanaan pretest sehingga pada pemberian perlakuan dan pada tahapan akhir diberikannya posttest.

Hasil studi pendahuluan peneliti pada siswa kelas IX SMP Teuku Umar Semarang terindikasi bahwa banyaknya siswa yang belum mampu memahami karier secara maksimal. Hal ini di tunjukkan berdasarkan data empiris dari Analisis Inventori Tugas Perkembangan (AITP) siswa dari kelompok wawasan dan persiapan karier dengan tingkat capaian rata-rata skor 3.81, sedangkan persentase Koefesien Varians adalah $26.06 \%$. Presentase ini diperkuat dari hasil kuesioner yang diberikan peneliti terhadap aspek pemahaman karier siswa dengan tingkat capaian berkisar pada persentase rata-rata $51.67 \%$.

Hasil ini dapat menjadi acuan yang kuat untuk melakukan penelitian lanjutan. Oleh karena itu, peneliti berkesempatan melakukan penelitian dengan memberikan intervensi karier kepada siswa dengan menggunakan teknik live modeling dan teknik symbolic modeling secara khusus. Sebagaimana Kantrov (2015) dalam penelitiannya mengungkapkan bahwa meningkatnya kemampuan karier siswa salah satunya intervensi yang harus di terapkan perlakuan khusus, yaitu dengan menciptakan sistem belajar yang bermakna yang memungkinkan siswa untuk belajar dan menerapkan pengetahuan dan keterampilan akademik dan teknik untuk tantangan dunia kerja

Hirschi \& Lage, (2008) dalam penelitiannya menemukan keterbatasan yang berdampak pada perkembangan kesiapan karier siswa dikarenakan intervensi yang di berikan bukanlah model perilaku yang di tunjukkan secara lansung. Dalam penelitian (Meijers, 2008) juga melaporkan bahwa intervensi yang terfokus untuk membantu siswa supaya berprestasi saja, tidak akan memberi efek positif terhadap siswa dalam mempersiapkan diri untuk berkarier.

Teknik live modeling merupakan teknik yang dapat memberi efek intervensi secara langsung kepada siswa dengan cara mendatangkan narasumber dari luar sebagai pedoman hidup untuk dipahami bagi siswa, dengan kata lain siswa dapat mengamati lansung contoh yang nyata (contoh hidup) sebagai pedomannya (Eford, 2016: 340). Oleh karena itu, penggunaan teknik live modeling dalam penelitian ini sangat berguna untuk membentuk kognitif serta perilaku-perilaku baru peserta didik melalui cara mengamati dan mencontoh tindakan orang lain sebagai modelnya yang diamati langsung, serta dapat memperkuat pemahaman dan menguatkan perilakuperilaku lain seperti cara berpikir terhadap cita-cita, kelemahan dan kelebihan yang dimiliki yang berhubungan dengan pemahaman karier siswa.

Sedangkan teknik symbolic modeling merupakan cara/prosedur yang dilakukan dengan melibatkan dan mengilustrasikan perilaku (model) yang ingin dicapai melalui video atau audio (Erford, 2016: 340). Rendahnya tingkat pemahaman karier siswa di sekolah akan berakibat fatal terhadap masa depan siswa. Oleh sebab itu, penanganan yang tepat dapat dilakukan dengan menggunakan teknik symbolic modeling. Efektifnya teknik symbolic modeling ini dapat menjadi acuan dan alasan yang mendasar sehingga pengunaan teknik symbolic modeling dapat diterapkan untuk meningkatkan pemahaman karier siswa.

Pemahaman karier merupakan aspek penting bagi siswa SMP, mereka yang memahami karier sendiri memiliki peluang yang besar terhadap citacitanya. Siswa yang memiliki pemahaman karier berarti telah memahami kemampuan, bakat minat, kelebihan maupun keterbatasan dirinya dan karier yang sesuai dengun dirinya, sehingga memiliki arah dan tujuan hidup yang realistis dimana mereka memiliki cita-cita yang sesuai dengan potensi dirinya. Pemahaman diri atau disebut knowing your self oleh Levinson, Ohter, Casweil dan Kiewra dalam (Brown, 2007: 261) merupakan aspek penting dalam pengambilan keputusan, yang selanjutnya kemampuan siswa dalam pengambilan keputusan karier merupakan wujud nyata dari kematangan perkembangan karier siswa.

Tujuan pemahaman karier siswa di sekolah adalah membantu mereka agar memperoleh pemahaman diri dan pengarahan dalam mempersiapkan diri terhadap studi lanjut dan pekerjaan yang berguna untuk masa depan. Oleh karena itu, semua siswa menerima pendidikan yang mengembangkan pengetahuan, keterampil-an, sikap dan nilai-nilai penting bagi kehidupan, sehingga mereka berada dalam posisi untuk membuat keputusan masa depan mereka (Vinci Ng \& Yuen. 2016).

Berdasarkan penjelasan di atas, penting bagi institusi pendidikan, terlebih bagi guru bimbingan dan konseling yang berkepentingan didalam berbagai persoalan dan permasalahan siswa disekolah, termasuk didalamnya siswa-siswa yang mengalami rendahnya tingkat pemahaman kariernya. Dalam hal ini, diharapkan supaya untuk menerapkan dengan menggunakan teknik symbolic modeling dan live modeling, teknik ini dapat menciptakan sistem belajar yang bermakna dan berorientasi masa depan karena 
sistem ini lebih memperhatikan aspek kognitif dan pembentukan prilaku baru siswa dengan cara mengamati langsung perilaku dari yang diamati.

\section{PENUTUP}

Penelitian ini telah dilakukan uji keefektifan layanan informasi karier dengan menggunakan teknik live modeling dan symbolic modeling untuk meningkatkan pemahaman karier siswa SMP Teuku Umar Semarang. Hasil penelitian menunjukkan subyek yang diberikan layanan informasi dengan menggunakan teknik live modeling dan symbolic modeling (kelompok eksperimen) memiliki peningkatan terhadap pemahaman kariernya dibandingkan dengan subyek penelitian yang tidak diberikan layanan layanan informasi karier (kelompok kontrol).

Selanjutnya, hasil penelitian ini diharapkan kepada institusi pendidikan dan guru konselor agar dapat menjadi acuan dan diterapkan di sekolah secara kontinu untuk meningkatkan kognitif siswa dibidang karier, dan dapat menjadi role model dalam pelaksanaan layanan karier disekolah. Dan juga dapat dijadikan sebagai salah satu rujukan atau referensi dimasa akan datang. Penelitian ini juga diharapkan dapat menjadi acuan bagi peneliti selanjutnya untuk menyempurnakan dari berbagai keterbatasan penelitian yang telah dilakukan oleh peneliti sebelumnya

\section{REFERENSI}

Atmaja, T. T. 2014. Upaya meningkatkan Perencanaan Karier Siswa Melalui Bimbingan Karier dengan Penggunaan Media Modul. Vol. 3, No 2. Jurnal Psikopedagogia.

Bertha, M. M. 2010. Career Course Impact an Adolescents' Levels Of Career Decision SelfEfficacy, Hope, and Self-Esteem. Doc. Of Philosophy: Northcentral University, Arizona.

Brown, D. 2007. Career Information, Career Counseling, Career Development (9th ed). Boston: Pearson Education, Inc.

Erford, T. B. 2016. Empat Puluh Teknik yang Harus Diketahui Setiap Konselor. Edisi Kedua. Terjemahan Helly P. S \& Sri M. S, Penerbit: Pustaka Pelajar.

Feldman, R. D., Olds, S.W. \& Papalia, D.E. 2009. Human Development (perkembangan manusia) Jakarta: Salemba Humanika.

Geurts, J., \& Meijers, F. 2009. Vocational education in The Netherlands: In search of a new identity. In R. Maclean \& D. N. Wilson (Eds.), International Handbook of Education for The Changing World of Work: Bridging Academic and Vocational Learning (pp. 483-499). New York, NY: Springer.
Hirschi, A., \& La"ge, D. 2008. Increasing The Career Choice Readiness of Young Adolescents: An Evaluation Study. International Journal for Educational and Vocational Guidance, 8, 95110.

Jennifer, N. K. 2010. High School Career Education: Student's Perceptions of the Life Planning Course. Ashland University.

Jasmi, A. M. \& Norwaliza, A. W. 2015. Effects of Career Exploration Module on Career Planning, Career Self-Efficacy and Career Maturity among Community College Students. Mediterranean Journal of Social Sciences. V6 N6 S1Doi: 10.5901/mjss.2015. v6n6s1p464

Kantrov, I. 2015. Career-Technical Education New Cte Model Is A Plus For Schools And Students. International Journal. Kappanmagazine. org. Academy of Information Technology and Robotics (AITR). V96 N6

Kevin B. S \& Tabitha L. Y. 2012. Applications of Motivational Interviewing in Career Counseling: Facilitating Career Transition. Journal of Career Development. 40(4) 329346. DOI: $10.1177 / 0894845312455508$.

Meijer F, Marinka K, \& Chad G. 2013. The Relationship Between Career Competencies, Career Identity, Motivation And Quality Of Choice. Vol. 47-66. International Jurnal Education Vocational Guidance. DOI 10.1007/s10775-012-9237-4.

Mustika, S. M. 2014. Pengembangan Layanan Informasi Karier Berbantuan Media Film untuk Meningkatkan Pemahaman Karier Siswa. ISSN 0854-1981. Jurnal Universitas Katolik Widya Mandala Madiun.

Schmidt, J. J. 2008. Counseling In Schools; Comprehensive Program of Responsive Services for All Student. USA: Pearson Education.

Sally E. R, \& John M. M. 2006. The Efficacy of Symbolic Modeling and Vicariou Reinforcement in Increasing Coping-Method Adherence. Journal Behavior Therapy 37 406-415. NSW, 2351

Trusty, J., Niles, S, G., \& Carney, J,V. 2005. Educational-Career Planning and Middle School Counselor. Journal Professional School Counseling. Vol 9 (2) (Online), (http://www. ProQuest Professional Education.com)

Vinci, N \& Mantak Y. 2016. Career Guidance and Counseling in an International School in Hong Kong: Literature Review and a School Counselor's Reflection. Asian Journal of Counselling, Published online first. 